\title{
A Resolução de Problemas na formação inicial: compreensões de futuros professores de Matemática
}

\author{
Problem Solving in initial training: understandings of the future mathematics \\ teacher
}

\author{
Jossara Bazílio de Souza Bicalho \\ Norma Suely Gomes Allevato \\ José Fernandes da Silva
}

\begin{abstract}
Resumo: Neste artigo, descrevemos uma pesquisa realizada a partir da aplicação de um questionário com 15 perguntas a um grupo de 17 estudantes de licenciatura em Matemática do Instituto Federal de Minas Gerais (IFMG), campus São João Evangelista, matriculados na disciplina Resolução de Problemas, do núcleo Práticas como Componente Curricular (PCC). Nosso objetivo foi levantar suas compreensões individuais acerca do potencial de inovação metodológica do ensino-aprendizagem-avaliação de Matemática através da resolução de problemas. Trata-se de uma pesquisa qualitativa, cuja análise de dados foi realizada a partir dos pressupostos da Análise Textual Discursiva (ATD). Os referencias teóricos perpassaram pela Resolução de Problemas, enquanto metodologia de ensino, e pela abordagem dos Conhecimentos do Professor de Matemática. Os futuros professores perceberam as habilidades
\end{abstract} que podem ser desenvolvidas pela Resolução de Problemas, enquanto ação e metodologia. Dessa forma, ficou evidente que a inovação metodológica no ensino de Matemática acontece quando a perspectiva da Resolução de Problemas é adotada.

Palavras-chave: Resolução de Problemas. Formação de Professores de Matemática. Conhecimentos do Professor de Matemática.

Abstract: In this article, we describe a research carried out from the application of a questionnaire with 15 questions to a group of 17 undergraduate students in Mathematics of the Instituto Federal de Minas Gerais (IFMG), campus São João Evangelista, enrolled in the discipline Problem Solving, from the Practices as a Curriculum Component (PCC). Our goal was to survey your individual understandings about the potential for methodological innovation in the teaching-learning-assessment of Mathematics through solving problem. It is a qualitative research, whose data analysis was performed based on the assumptions of Textual Discursive Analysis (ATD). The theoretical references went through Problem Solving, as a teaching methodology, and by the Mathematics Teacher Knowledges approach. The future teachers realized the skills that can be developed by Problem Solving, as an action and methodology. Thus, it was evident that the methodological innovation in the teaching of Mathematics happens when the perspective of Problem Solving is adopted.

Jossara Bazílio de Souza Bicalho Doutoranda em Ensino de Ciências e Matemática. Professora do Instituto Federal de Educação, Ciência e Tecnologia de Minas Gerais (IFMG), campus São João Evangelista. Minas Gerais, Brasil.

iD orcid.org/0000-0001-7866-6206 $\bowtie$ jossara.bicalho@ifmg.edu.br

Norma Suely Gomes Allevato Doutora em Educação Matemática. Professora do Programa de Pós-Graduação em Ensino de Ciências e Matemática da Universidade Cruzeiro do Sul (UNICSUL). São Paulo, Brasil

iD orcid.org/0000-0001-6892-606X $\bowtie$ normallev@gmail.com José Fernandes da Silva Doutor em Educação Matemática. Professor do Instituto Federal de Educação, Ciência e Tecnologia de Minas Gerais (IFMG), campus São João Evangelista. Minas Gerais, Brasil. iD orcid.org/0000-0002-5798-5379 $\bowtie$ jose.fernandes@ifmg.edu.br

Recebido em 24/06/2020 Aceito em 04/08/2020 Publicado em 11/09/2020

Keywords: Problem Solving. Mathematics Teacher Training. Mathematics Teacher Knowledge. 


\section{Introdução}

Recentemente, durante o isolamento social recomendado pela Organização Mundial de Saúde (OMS), assistimos a uma live (transmissão ao vivo via rede social) com o professor Dario Fiorentini, da Universidade Estadual de Campinas (UNICAMP). Pesquisador, entre outros temas, de formação de professores, ele discorreu sobre a formação de professores e os desafios que serão trazidos pela Resolução CNE/CP n 2, de 20 de dezembro de 2019: a Base Nacional Comum da Formação de Professores (BNCFP) (BRASIL, 2019). O documento supracitado encarrega-se de apresentar diretrizes para o processo formativo dos professores tendo como base as competências relacionadas ao conhecimento, à prática e ao engajamento profissional. Contudo, a BNCFP apresenta-se como um documento que, em sua gênese, careceu de debates e reflexões com a comunidade educacional e acadêmica (RODRIGUES, PEREIRA e MOHR, 2019). Um dos exemplos para a falta de diálogo é a subserviência da BNCFP à Base Nacional Comum Curricular (BNCC), que da mesma forma, segundo os citados autores, foi construída de forma verticalizada.

No programa Formação de professores: o que vem por aí?, professor Fiorentini mencionou o conhecimento especializado do professor, segundo Shulman $(1986,1987)$, quando destacou que, ao professor, neste caso o de Matemática, conhecer o conteúdo a ser ensinado é uma condição necessária, "mas está longe de ser suficiente ${ }^{1 "}$. Quais elementos então devem ser incorporados à formação inicial e continuada dos professores de Matemática? O objetivo do nosso trabalho vai ao encontro dessa expectativa.

Esta pesquisa, de caráter qualitativo, tem o objetivo de levantar e analisar as compreensões de 17 estudantes de Licenciatura em Matemática, na condição de alunos ainda na formação inicial de professor, sobre a inovação na prática pedagógica na perspectiva da metodologia de Ensino-Aprendizagem-Avaliação de Matemática através da Resolução de Problemas. Foram inqueridos os alunos matriculados na disciplina obrigatória Resolução de Problemas, oferecida no $6^{\circ}$ período do curso de graduação, do Instituto Federal de Educação, Ciência e Tecnologia de Minas Gerais (IFMG), campus São João Evangelista. Foi aplicado um questionário de 15 perguntas, das quais foram selecionadas as respostas às questões $8,9,10$, 11, 12 e 13, cujo conteúdo mostrou-se mais alinhado ao objetivo delineado para o presente estudo.

Este artigo foi organizado em seis seções, incluindo esta Introdução e as Referências. $\mathrm{Na}$

\footnotetext{
1 Live com Dario Fiorentini no canal Matemática Humanista, em 23 abr. 2020. Disponível em: https://www.youtube.com/watch?v=d0jYp0Un2uo\&t=1172s; acesso em 24 abr. 2020.
} 
Introdução apresentamos o contexto e o objetivo da pesquisa. Na segunda seção, destacamos as pesquisas de Allevato e Onuchic $(2014,2019)$ e Onuchic e Allevato $(2009,2011,2012,2015)$, discorrendo sobre o conceito de problema, sobre a importância da resolução de problemas no contexto do ensino de Matemática e acerca da metodologia tríplice de ensino-aprendizagemavaliação, com a descrição das etapas sugeridas pelas autoras brasileiras para o trabalho com a resolução de problemas em sala de aula. Na terceira seção, resgatamos as discussões sobre 0 conhecimento do professor, de Shulman (1986, 1987); sua ampliação para o conhecimento do professor de Matemática, por Ball, Thames e Phelps (2008); passando pelo Conhecimento Didático Matemático (CDM) (BREDA et al., 2018; GODINO, 2009; GODINO et al., 2017; KAIBER, LEMOS e PINO-FAN, 2017; PINO-FAN, FONT e GODINO, 2013; PINO-FAN, GODINO e FONT, 2011 ); e chegando, finalmente, ao Conhecimento Especializado dos Professores de Matemática - Mathematics Teachers' Specialised Knowledge (CARRILLO et al., 2019). Na quarta seção, apresentamos o contexto da pesquisa, o percurso metodológico e a descrição e análise dos dados, orientada pela Análise Textual Discursiva (ATD), de Moraes e Galiazzi (2016). E, por fim, as Considerações Finais e as Referências.

\section{Resolução de Problemas: uma metodologia de Ensino-Aprendizagem-Avaliação}

A conjuntura educacional atual aponta para a necessidade de reformas curriculares e metodológicas em todas as disciplinas escolares, destacadamente na Matemática. Em relação à revisão dos modelos de ensino-aprendizagem, ressalta-se que professores e profissionais da Educação Básica precisarão aprofundar-se em compreensões acerca de como implementar 0 ensino dos conteúdos de Matemática através da resolução de problemas (BICALHO, 2018).

Mas o que é a Resolução de Problemas? Para explicitar a definição desse conceito, tão valorizado nos currículos de Matemática, primeiro necessário se faz definir problema. Para Van de Walle (2009, p. 57), "um problema é qualquer tarefa ou atividade na qual os estudantes não tenham nenhum método ou regra já receitados ou memorizados e nem haja uma percepção por parte dos estudantes de que haja um método 'correto' específico de solução". Para Onuchic e Allevato (2011, p. 81), "é tudo aquilo que não se sabe fazer, mas que se está interessado em fazer", acrescentando que "um problema se configura na relação com o resolvedor, de tal modo que, se ele já conhece ou tem memorizados tais métodos de resolução ou não está interessado na atividade, não será para ele um problema" (ALLEVATO e ONUCHIC, 2014, p. 44). 
Cai e Lester (2012) afirmam que, ao professor, cabe a função de colaborar para que seus alunos se tornem eficientes solucionadores de problemas, advertindo que "as habilidades dos alunos em resolver problemas frequentemente se desenvolvem lentamente, exigindo, assim, uma atenção assistida, em longo prazo, para tornar a resolução de problemas uma parte integrante do programa de matemática" (p. 156).

Onuchic e Allevato (2011) apontam vantagens em se trabalhar com a resolução de problemas. Empoderamento matemático, autonomia, confiança e autoestima são observados nos alunos que a praticam. E aos professores, o principal ganho é a inovação na sua prática pedagógica: avaliação contínua e processual, para a tomada de decisões instrucionais em prol do sucesso matemático dos alunos; a inversão na dinâmica da aula de Matemática, tendo o problema como ponto de partida para a aprendizagem; a formalização dos conceitos e teorias feita no final do processo. Assim, passa-se a vivenciar um ensino-aprendizagem-avaliação de Matemática mais significativo, para alunos e professores. E seus papéis são invertidos e ressignificados no processo educativo, tal como aponta Freire apud Skovsmose (2013), ao discutir a relação professor-alunos:

\footnotetext{
Através do diálogo, o professor-dos-estudantes e os estudantes-do-professor se desfazem e um novo termo emerge; professor-estudante com estudantes-professores. 0 professor não é mais meramente o o-que-ensina, mas alguém a quem também se ensina no diálogo com os estudantes, os quais, por sua vez, enquanto estão ensinando, também aprendem. Eles se tornam conjuntamente responsáveis por um processo no qual todos crescem. (FREIRE² apud SKOVSMOSE, 2013, p. 17).
}

Diversos autores, no mundo inteiro, vêm se empenhado em fazer acontecer o ensinoaprendizagem-avaliação de Matemática através da resolução de problemas nas salas de aula da Educação Básica. Entre eles, estão as pesquisadoras brasileiras Norma Allevato e Lourdes Onuchic, que se dedicaram à elaboração e descrição detalhada da metodologia que consideram "um caminho para ensinar Matemática e não apenas para ensinar a resolver problemas" (ONUCHIC e ALLEVATO, 2009, p. 8). Assim, apontam uma ressignificação para a Resolução de Problemas nos currículos de Matemática, considerando o problema como "um ponto de partida e orientação para a aprendizagem, e os professores, através e durante a resolução dos problemas, devem fazer conexões entre os diferentes ramos da Matemática, gerando novos conceitos e novos conteúdos" (ONUCHIC e ALLEVATO, 2009, p. 8).

Allevato e Onuchic (2014) indicam que há três perspectivas coexistentes acerca de

\footnotetext{
2 FREIRE, Paulo. Pedagogy of the Opressed. Nova York: Herder and Herder, 1972.
} 
resolução de problemas no contexto do ensino de Matemática: (1) o ensino sobre Resolução de Problemas; (2) o ensino para a resolução de problemas; e (3) o ensino através da resolução de problemas. Cada uma dessas concepções possui implicações pedagógicas diferentes. A primeira teoriza a Resolução de Problemas, relacionando-a especialmente às heurísticas, que encontra em Pólya (1887-1985) e em seu clássico livro $A$ arte de resolver problemas (PÓLYA, 1945) seu maior expoente. Mais popular entre os professores de Matemática, a segunda abordagem, do ensino para a resolução de problemas, está relacionada ao tratamento tradicional de apresentação dos conteúdos matemáticos para fins de instrumentalização para a resolução, a posteriori, de problemas. Percebe-se uma visão ingênua nesta abordagem de que há uma relação direta entre conhecer o conteúdo matemático e estar apto para resolver problemas. Allevato e Onuchic (2014, p.38) alertam que "um perigo dessa concepção é que ela configure a resolução de problemas como uma atividade que os alunos só podem realizar após a introdução de um novo conceito, ou após o treino de alguma habilidade ou de algum algoritmo."

Aqui, aproveitamos para esclarecer que as expressões resolução de problemas, com r e p minúsculos e Resolução de Problemas, com $\mathrm{R}$ e $\mathrm{P}$ maiúsculos, serão usados ao longo deste artigo buscando fazer referência ao ato de resolver problemas e à metodologia/teoria, respectivamente. A Resolução de Problemas, como processo constituído de dez etapas, com a finalidade de guiar o professor de Matemática na efetivação da metodologia de ensinoaprendizagem-avaliação, é assim descrita por Allevato e Onuchic (2014):

(1) proposição do problema; (2) leitura individual; (3) leitura em conjunto; (4) resolução do problema; (5) observar e incentivar; (6) registro das soluções na lousa; (7) plenária; (8) busca de consenso; (9) formalização do conteúdo; (10) proposição e resolução de novos problemas. (p. 45).

A Resolução de Problemas, na concepção de Allevato e Onuchic (2014), carrega em si a completude da tarefa do professor e da professora de Matemática: ensinar e fazer aprender, revendo, tanto quanto necessário, as ações nas salas de aula de Matemática. Ensinar, aprender e avaliar, para ensinar melhor e aprender melhor. Nisto consiste a metodologia tríplice de ensinoaprendizagem-avaliação de Matemática através da resolução de problemas. Neste processo, "0 professor é o guia, o orientador dos processos de construção do conhecimento e os alunos são co-construtores desse conhecimento" (ALLEVATO e ONUCHIC, 2019, p. 3).

A metáfora da construção, presente na citação acima, é considerada como constituinte do primeiro princípio da teoria de aprendizagem Construtivismo: "o conhecimento não é recebido 
passivamente, mas é construído ativamente pelo sujeito cognitivo" (VON GLASERFELD 3 apud ERNEST, 2010, p. 40). O conhecimento é ativo, individual e pessoal, e se baseia em conhecimentos previamente construídos (ERNEST, 2010, p. 40). 0 educador matemático inglês Paul Ernest retoma, ainda, o conceito de educação bancária, do educador brasileiro Paulo Freire: "Freire (1972) critica o modelo de aprendizado 'bancário', no qual itens inertes do conhecimento são repassados para os alunos, que precisam absorvê-los, tornando-se receptores passivos, em vez de agentes sociais epistemológicos e politicamente capacitados" (ERNEST, 2010, p. 40).

Quando o educador matemático George Pólya (1887-1985) apresentou sua heurística para a resolução de qualquer problema, ele também discutiu a importância de professores de Matemática tornarem-se resolvedores de problemas, para que seus alunos experimentem, com êxito, a Resolução de Problemas, enquanto metodologia de ensino-aprendizagem de Matemática (FELMER e PERDOMO-DÍAZ, 2016). Van de Walle (2009) defende a Resolução de Problemas, enquanto metodologia centrada no aluno, como a melhor abordagem para o ensino de Matemática: "as pesquisas em educação matemática constantemente revelam que a compreensão e as habilidades são desenvolvidas melhor quando os estudantes têm permissão para investigar novas ideias, criar e defender soluções para problemas e participar em uma comunidade de aprendizagem Matemática" (VAN DE WALLE, 2009, p. 9). E acrescenta: "O ensino com tarefas e discussão em sala de aula baseado em resolução de problemas é uma mudança radical das experiências vividas pela maioria dos professores" (VAN DE WALLE, 2009, p. 15).

\section{Sobre os conhecimentos de professores de Matemática}

Os conhecimentos que os professores necessitam colocar em jogo em sala constituem objeto de investigação em diferentes grupos de pesquisa. Os debates iniciaram por volta dos anos 1980 com as publicações de Lee Shulman. Em 1986, o esse autor propôs o conhecimento do conteúdo, o conhecimento pedagógico do conteúdo e o conhecimento do currículo. Tais categorias foram definidas da seguinte forma: Conhecimento do conteúdo: o universo de conceitos, regras e definições que compõem o conteúdo específico da disciplina que o docente leciona; Conhecimento pedagógico do conteúdo: envolve o conhecimento da disciplina sob a responsabilidade do professor, porém, engloba as estratégias para o ensino dos conteúdos; Conhecimento do

\footnotetext{
3 VON GLASERSFELD, E. Constructivism in Education. In: HUSEN, Torsten; POSTLETHWAITE, Neville. (Org.).
} Internacional Encyclopedia of Education. Oxford: Pergamon, 1989, p. 162-163. 
currículo: envolve o conhecimento das diretrizes curriculares e as relações intra e extra disciplinar.

Ampliando as categorias supracitadas, Shulman (1987) propõe um avanço, ao afirmar que, no mínimo, o conjunto de conhecimentos dos professores deveria incluir:

Conhecimento de conteúdo; Conhecimento pedagógico geral; Conhecimento de currículo; Conhecimento de conteúdo pedagógico, em particular a mistura especial de conteúdo e pedagogia; Conhecimento sobre os alunos e de suas características; Conhecimento do contexto educacional; Conhecimento dos fins, propósitos e valores educacionais e sua base filosófica e histórica. (SHULMAN, 1987, p. 8).

Posteriormente, outros modelos de conhecimentos dos professores, como o de Grossman (1990), buscaram elaborar novas categorias com base em Shulman (1986, 1987). Contudo, os modelos citados possuem características genéricas. Avanços em tais discussões foram e são necessários (MORIEL JUNIOR e WIELEWSKI, 2017), pois as próprias mudanças sociais, tecnológicas, culturais e econômicas impactam a sala de aula. Além do exposto, a formação de professores, com destaque para a inicial, necessita refletir sobre os conhecimentos especializados. Um dos modelos com repercussão significativa na formação de professores de Matemática foi o de Ball, Thames, Phelps (2008), Mathematical Knowledge for Teaching (MKT), apresentado no Quadro 1.

Quadro 1: Modelo de conhecimento de professores de Matemática

\begin{tabular}{|c|c|c|}
\hline \multirow{3}{*}{ 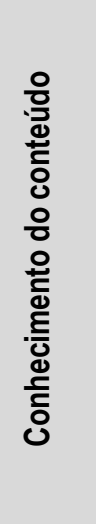 } & $\begin{array}{l}\text { Conhecimento comum do } \\
\text { conteúdo }\end{array}$ & $\begin{array}{l}\text { Refere-se ao conhecimento que não é característico apenas do professor } \\
\text { de Matemática, mas comum às profissões que se valem dos } \\
\text { conhecimentos matemáticos para desenvolver suas funções. }\end{array}$ \\
\hline & $\begin{array}{l}\text { Conhecimento } \\
\text { especializado do conteúdo }\end{array}$ & $\begin{array}{l}\text { Vai além do conhecimento comum do conteúdo, isto é, são requeridas } \\
\text { competências necessárias para a condução do trabalho docente na } \\
\text { Matemática. }\end{array}$ \\
\hline & $\begin{array}{l}\text { Conhecimento do horizonte } \\
\text { matemático }\end{array}$ & $\begin{array}{l}\text { Está relacionado com a forma pela qual os professores situam o } \\
\text { conteúdo no âmbito do currículo. Assim, ao ensinar um determinado } \\
\text { conteúdo em uma série/ano/nível o professor necessita conhecer sua } \\
\text { importância e os aprofundamentos necessários para - e nas - fases } \\
\text { seguintes. }\end{array}$ \\
\hline \multirow{3}{*}{ 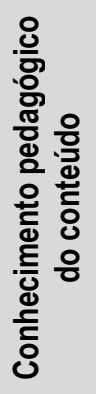 } & $\begin{array}{l}\text { Conhecimento do conteúdo } \\
\text { e dos alunos }\end{array}$ & $\begin{array}{l}\text { Diz respeito às habilidades que o professor deve possuir para lidar com } \\
\text { o saber dos alunos e o saber da Matemática. }\end{array}$ \\
\hline & $\begin{array}{l}\text { Conhecimento do conteúdo } \\
\text { e do ensino }\end{array}$ & $\begin{array}{l}\text { Evidencia o diálogo entre o saber matemático e o saber sobre o ensino, } \\
\text { discernimento que possibilita mediar discussões, selecionar, organizar } \\
\text { ou elaborar tarefas, alternar metodologias e repensar estratégias. }\end{array}$ \\
\hline & Conhecimento do currículo & $\begin{array}{l}\text { Refere-se a conhecer as orientações curriculares propostas, os } \\
\text { diferentes meios e recursos para ensinar conteúdos matemáticos e à } \\
\text { capacidade de selecionar e organizar diferentes currículos. }\end{array}$ \\
\hline
\end{tabular}

Fonte: Ball, Thames e Phelps (2008) 
Contudo, Godino (2009) destaca que os modelos propostos carecem de indicadores para avaliar e fomentar os diferentes conhecimentos necessários ao professor de Matemática. PinoFan, Font e Godino (2013, p. 138-139) apontam que, apesar dos avanços propostos por Ball, Thames e Phelps (2008), questões fundamentais ainda emergem sobre os conhecimentos dos professores de Matemática, tais como Como determinar o conhecimento didático e matemático com modelos que incluem categorias muito globais? Concretamente, de que forma ou de acordo com quais critérios pode-se avaliar ou medir o MKT? Como se pode ajudar os professores a adquirir ou desenvolver os distintos componentes do MKT? A partir destas inquietações, outras investigações ocuparam-se em discutir o conhecimento ampliado do professor de Matemática.

O modelo do Conhecimento Didático Matemático (CDM) foi gestado no âmbito do Enfoque Ontossemiótico (EOS) (GODINO et al., 2017). Tal construto teórico nasceu no seio da Didática da Matemática, com objetivo de articular diferentes pontos de vista e noções teóricas sobre 0 conhecimento matemático, seu ensino e sua aprendizagem. (BREDA et al., 2018; GODINO, 2009; GODINO et al., 2017; KAIBER, LEMOS e PINO-FAN, 2017; PINO-FAN, FONT e GODINO, 2013). O CDM é composto por seis facetas (Figura 1), as quais apontam os conhecimentos requeridos aos professores de Matemática.

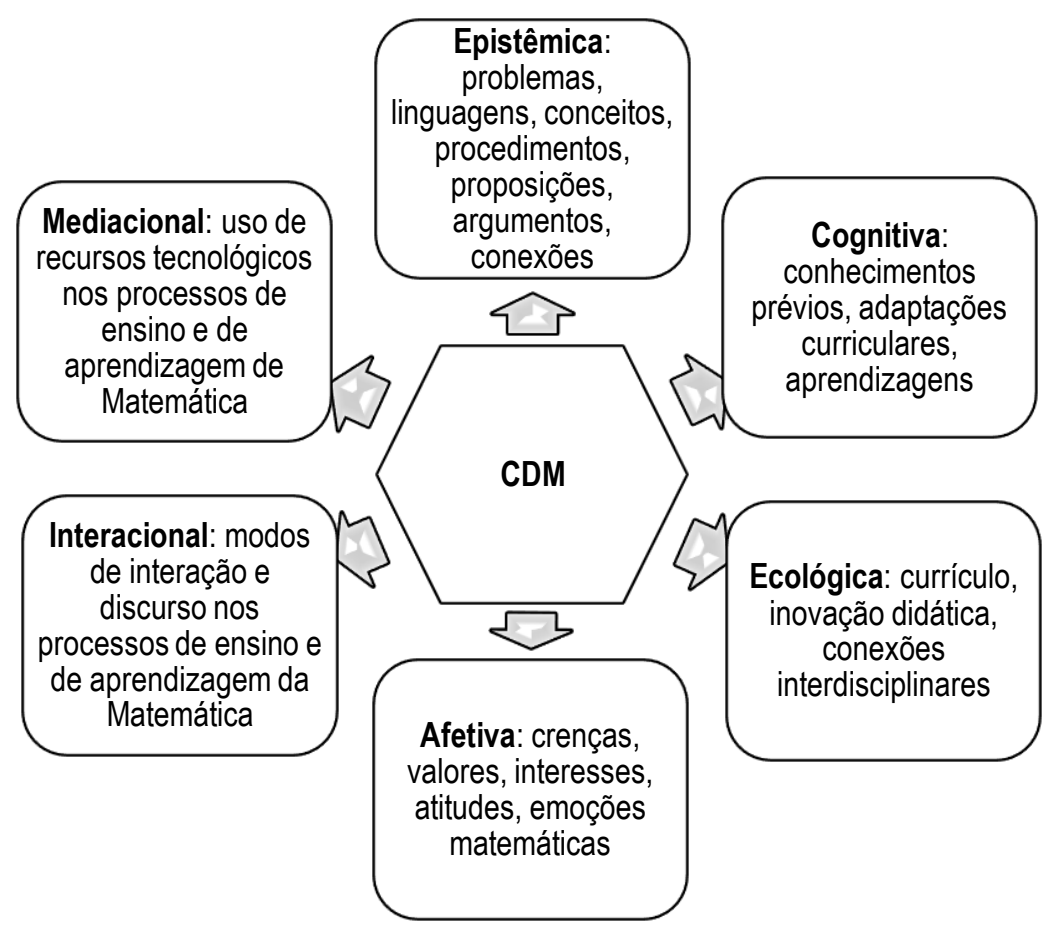

Figura 1: Facetas do CDM (GODINO, 2009)

Desta discussão emerge o termo conhecimento ampliado do conteúdo (PINO-FAN e GODINO, 2015) que constitui uma extensão do conhecimento do horizonte matemático, proposto 
por Ball, Thames e Phelps (2008). Tal conhecimento

provê ao professor as bases matemáticas necessárias para planejar novos desafios matemáticos na aula, vincular o objeto matemático que se está estudando com outras noções matemáticas e encaminhar os alunos ao estudo das noções matemáticas subsequentes àquela que está em estudo. (PINO-FAN e GODINO, 2015, p. 97).

Conforme supracitado, o CDM é uma ampliação do modelo MKT. Pelo exposto, percebese a complexidade dos conhecimentos para a docência. As investigações e avanços nessa discussão são fundamentais para que os cursos de formação de professores de Matemática possam refletir sobre seus currículos. Tal perspectiva nos remete aos dizeres de Carrillo et al. (2019), quando afirmam que

mais do que diferentes maneiras de ensinar um item, existem diferentes maneiras de conhecê-lo e que, sem entrar em questões sobre a utilidade de outro conhecimento distinto da Matemática (como a psicologia educacional), os fundamentos do conhecimento dos professores de Matemática estão dentro da própria Matemática e da sua consideração como um objeto de aprendizagem e ensino. (p. 299).

Carrillo et al. (2019) fazem uma associação direta entre o Mathematics Teachers' Specialised Knowledge (MTSK), ou seja, Conhecimento Especializado de Professores de Matemática, e o gerenciamento de tarefas de sala de aula para resolução de problemas. Apoiados em Shulmann $(1986,1987)$, destacam que conhecer o conteúdo a ser ensinado é uma condição necessária, mas não suficiente para ensinar Matemática efetivamente. Isto é, não é verdadeira a premissa que segue: se o professor de Matemática tem domínio do conteúdo então é garantido que o ensino-aprendizagem do conteúdo será efetivo.

Vários questionamentos emergem da ação didática do professor - ou do ato de investigar, dos pesquisadores - durante uma aula com Resolução de Problemas, e todos eles conduzem ao conhecimento especializado do professor de Matemática (MTSK):

\footnotetext{
Por que devo definir esse problema para meus alunos? Como? Esse contexto é interessante para eles? É um problema para meus alunos aplicarem o que já aprenderam ou irão construir novos conhecimentos? Que soluções existem e quantas maneiras há de abordar esse problema? Como meus alunos resolverão isso? Que tipo de dificuldades meus alunos enfrentarão, e serão iguais para todos eles? Como posso gerenciar essas dificuldades? Que tipo de ajuda devo Ihes dar? Seria possível estender o problema, usando uma estratégia "e se ...", por exemplo? Que conhecimento eu provavelmente precisarei gerenciar durante a resolução desse problema? (CARRILLO et al., 2019, p. 297).
}

Essa abordagem relacionada aos conhecimentos para a docência justifica-se pelo fato 
desta investigação ter como objetivo analisar as experiências e compreensões dos estudantes de Licenciatura em Matemática acerca da metodologia Ensino-Aprendizagem-Avaliação através da Resolução de Problemas. Enquanto futuros mestres, estes constroem e reconstroem seus conhecimentos de acordo com as vivências e práticas no âmbito do processo formativo.

\section{Contexto e percurso metodológico}

"A educação é um campo de estudo, um local que contém fenômenos, eventos, instituições, problemas, pessoas e processos que, por si sós, constituem a matéria-prima para investigações de muitos tipos" (SHULMAN4 apud ONUCHIC e ALLEVATO, 2012, p. 249). Nossa investigação é do tipo pesquisa qualitativa, que pretendeu levantar as compreensões individuais acerca do ensino de Matemática através da resolução de problemas, a partir da condição dos participantes como estudantes em formação inicial de professores de Matemática; "em vez da defesa com números, nas abordagens qualitativas é preciso fazê-la com argumentos" (MORAES e GALLIAZI, 2016).

Optamos pelo questionário como procedimento metodológico, assumindo que a pesquisa qualitativa pode se iniciar com a manifestação oral ou escrita dos sujeitos e que a fala/linguagem traduz a essência do ser e dos fenômenos (MORAES e GALLIAZI, 2016). Os participantes na pesquisa foram 17 estudantes da Licenciatura em Matemática do IFMG, campus São João Evangelista. Foram inquiridos os estudantes matriculados na disciplina obrigatória Resolução de Problemas, situada no $6^{\circ}$ período do curso de graduação, segundo consta na matriz curricular apresentada no Projeto Pedagógico do Curso (PPC) (IFMG, 2018). No Quadro 2, são mostrados detalhes da disciplina, segundo consta no PPC. O questionário foi aplicado em dezembro de 2019, durante cerca de 100 min (2 horas/aula), em horários cedidos pelo professor da disciplina, após esclarecimentos sobre a investigação em questão e a assinatura do Termo de Consentimento Livre e Esclarecido (TCLE).

O questionário submetido aos estudantes foi do tipo semiestruturado, composto de 15 perguntas, com opção de respostas objetivas e solicitação de justificativas. As questões de 1 a 7 versaram sobre as experiências do estudante com a disciplina escolar Matemática, na Educação Básica (Anos Finais do Ensino Fundamental e Ensino Médio). Para fins deste estudo, será

\footnotetext{
${ }^{4}$ SHULMAN, Lee. Disciplines of Inquiry in Education: an overview. In: JAEGER, Richard M. (Ed.). Complementary
} Methods for Research in Education. Washington: American Educational Research Association, 1988, p. 3-20. 
considerado como corpus da pesquisa o conjunto de respostas dadas às questões de 8 a 13, que pretenderam investigar as experiências com a Resolução de Problemas durante a formação inicial desses futuros professores. Portanto, o texto-base para o presente estudo constituiu-se das respostas escritas dos licenciandos, identificados anonimamente por um dos números cardinais, na sequência de 1 a 17.

Quadro 2: Disciplina obrigatória Resolução de Problemas

\begin{tabular}{|c|c|c|c|}
\hline \multicolumn{2}{|c|}{$6^{\circ}$ período } \\
\hline \multicolumn{2}{|c|}{ Código: RP } & Nome da disciplina: Resolução de Problemas \\
\hline Carga horária total: $30 \mathrm{~h}$ & Abordagem metodológica: & Natureza: \\
CH teórica: $20 \mathrm{~h}$ & CH prática: 10h & Teórica/prática & Obrigatória \\
\hline
\end{tabular}

Fonte: IFMG (2018, p. 65)

Para a análise dos dados, foi utilizada a Análise Textual Discursiva (ATD), uma metodologia que consiste na elaboração de metatextos analíticos, descritivos e interpretativos, carregados de sentidos e significados, construídos pelos pesquisadores a partir de seus conhecimentos, intenções e teorias, em relação ao conjunto de textos ou documentos examinados (MORAES e GALLIAZI, 2016). Imbuídos do que apontam Moraes e Galliazi (2016), buscamos realizar uma leitura a partir da perspectiva dos sujeitos investigados, despindo-nos de nossas próprias ideias e teorias.

\subsection{Definindo as Unidades de Significado}

Tendo definido e delimitado o corpus da pesquisa, iniciamos o ciclo de análise pela Unitarização. A unitarização consiste na fragmentação do texto e codificação de cada unidade, podendo ser atribuído um nome ou título para cada uma, o que equivale à interpretação preliminar do pesquisador, segundo Andreatta e Allevato (2020).

Neste estudo, a unitarização deu-se a partir das respostas dos participantes ao questionário aplicado. As unidades originaram-se, portanto, daquele texto, a partir das primeiras interpretações que realizamos, com interlocução empírica e teórica, ou seja, com as conexões estabelecidas com situações similares e com o referencial teórico, como sugerem Moraes e Galliazi (2016). Os fragmentos do texto analisado foram identificados por códigos, passando a constituir, dessa forma, as Unidades de Análise ou Unidades de Significado. O código de cada 
Unidade de Significado (US) deve ser estabelecido com vias a identificar a origem do fragmento de texto. Neste estudo, US 8.2 é o código do primeiro fragmento de texto ao qual se atribuiu um significado (Quadro 3) e a US 13.8 foi a última unidade de significado catalogada (Quadro 9). Na sequência numérica, em algarismos indo-arábicos, o primeiro número, de 8 a 13, relaciona-se ao número da questão respondida; o segundo, que varia de 1 a 17, refere-se a cada um dos estudantes participantes na pesquisa, identificados anonimamente. Assim, o código US 10.12 refere-se à unidade de significado extraída de uma resposta dada pelo estudante E12 à décima pergunta do questionário.

As unidades de significado extraídas das respostas dos estudantes da Licenciatura em Matemática foram organizadas em quadros com três colunas, inspirados no modelo adotado por Andreatta e Allevato (2020): a primeira coluna foi preenchida com o código numérico da unidade de significado (US); a segunda coluna traz trechos das respostas dos participantes às questões; e, na terceira coluna, apresentam-se as primeiras interpretações dos pesquisadores, por meio das quais se deu um título para a unidade de significado. Sendo assim, a apresentação dos dados da pesquisa está organizada no conjunto de quadros apresentados nesta seção (Quadros 3 a 9). Os comentários e discussões acerca do conteúdo dos quadros são apresentados nas seções seguintes: da Categorização e da Comunicação dos Dados.

Quadro 3: Unidades de significado nas respostas à questão 8

\begin{tabular}{|c|c|c|}
\hline \multicolumn{2}{|c|}{$\begin{array}{c}\text { QUESTÃO 8. Você se recorda se em alguma disciplina da Licenciatura em Matemática o(a) professor(a) } \\
\text { trabalhou com Resolução de Problemas? ( ) Sim. ( ) Não. Se sim, como foi esse trabalho? }\end{array}$} \\
$\begin{array}{c}\text { Código } \\
\text { da US }\end{array}$ & \multicolumn{1}{|c|}{ Fragmentos de textos das respostas dos estudantes } & \multicolumn{2}{|c|}{$\begin{array}{c}\text { Título da US } \\
\text { (Interpretações } \\
\text { preliminares dos } \\
\text { pesquisadores) }\end{array}$} \\
\hline 8.2 & $\begin{array}{l}\text { Sim. Na resolução de listas de exercícios das disciplinas: Álgebra } \\
\text { Linear, Matemática Financeira e Teoria dos Números, embora o título } \\
\text { seja "exercícios", todas as questões eram contextualizadas. }\end{array}$ & $\begin{array}{l}\text { Ideia de problema } \\
\text { associado a contextos da } \\
\text { vida real }\end{array}$ \\
\hline 8.3. & $\begin{array}{l}\text { Sim. [...] aulas de Estatística [...] lista com questões contextualizadas e } \\
\text { deveríamos resolvê-la em grupos [...] Matemática Financeira, Álgebra, } \\
\text { porém nunca adotaram o roteiro proposto por Onuchic e Allevato. }\end{array}$ & $\begin{array}{l}\text { Contextos da vida real } \\
\text { sem o ensino através da } \\
\text { resolução de problemas } \\
\text { (rp) }\end{array}$ \\
\hline 8.5 & $\begin{array}{l}\text { Sim. Algumas disciplinas são mais propícias para trabalhar com RP; } \\
\text { lembro de tê-la visto em conteúdos como Matemática Financeira ou em } \\
\text { Cálculo 2 com cálculos de áreas. }\end{array}$ & $\begin{array}{l}\text { Conteúdos matemáticos } \\
\text { mais propícios ao ensino } \\
\text { com rp }\end{array}$ \\
\hline 8.11 & $\begin{array}{l}\text { Sim. Durante as disciplinas didáticas sempre foram trabalhados } \\
\text { problemas e, após, uma plenária para discutir os problemas. Nas outras } \\
\text { disciplinas, as teóricas e puras, apareciam problemas, mas não se }\end{array}$ & $\begin{array}{l}\text { Discussão dos problemas } \\
\text { nas disciplinas }\end{array}$ \\
\hline
\end{tabular}




\begin{tabular}{|c|l|l|}
\hline 8.13 & discutiam sobre eles. & didáticas \\
\hline 8.15 & $\begin{array}{l}\text { Sim. Realizamos uma pesquisa, definimos como aplicaríamos uma } \\
\text { oficina em uma escola, apresentamos um problema para os alunos } \\
\text { participantes (problema de combinatória) e desenvolvemos métodos } \\
\text { para chegarmos em uma solução sem uso de fórmulas. }\end{array}$ & $\begin{array}{l}\text { Resolução de Problemas } \\
\text { (RP) em oficinas na } \\
\text { Educação Básica }\end{array}$ \\
\hline 8.17 & $\begin{array}{l}\text { Sim. Uma que me chamou bastante a atenção foi a disciplina Ensino de } \\
\text { trabalhara a RP com os estudantes através de oficinas. Os estudantes } \\
\text { adoraram. }\end{array}$ & $\begin{array}{l}\text { Oficinas com RP na } \\
\text { Educação Básica }\end{array}$ \\
\hline $\begin{array}{l}\text { Sim. Foram resolvidas situações problemas aplicando a matéria } \\
\text { aprendida tanto em atividades em sala quanto em provas. (Grifo nosso). }\end{array}$ & $\begin{array}{l}\text { Ensinar para resolver } \\
\text { problemas }\end{array}$ \\
\hline
\end{tabular}

Fonte: Elaborado pelos Autores

Quadro 4: Unidades de significado nas respostas à questão 9

\begin{tabular}{|c|c|c|}
\hline \multicolumn{2}{|c|}{$\begin{array}{l}\text { QUESTÃO 9. Você já estudou sobre a metodologia de Ensino-aprendizagem-avaliação de Matemática através } \\
\text { da RP durante o curso de Licenciatura em Matemática? ( ) Sim. ( ) Não. } \\
\text { Se sim, enumere autores, artigos, livros, dissertações, teses, entre outros. }\end{array}$} \\
$\begin{array}{c}\text { Código } \\
\text { da US }\end{array}$ & \multicolumn{1}{|c|}{ Fragmentos de textos das respostas dos estudantes } & $\begin{array}{c}\text { Título da US } \\
\text { (Interpretações } \\
\text { preliminares dos } \\
\text { pesquisadores) }\end{array}$ \\
\hline 9.4 & $\begin{array}{l}\text { Sim. A aluna Isabela5 produziu seu TCC sobre RP tendo como referência } \\
\text { Onuchic e Allevato. }\end{array}$ & $\begin{array}{l}\text { RP em Trabalho de } \\
\text { Conclusão de Curso } \\
\text { (TCC) da instituição }\end{array}$ \\
\hline 9.10 & $\begin{array}{l}\text { Sim. Sempre estudamos esses assuntos, mas no momento não consigo } \\
\text { citar nada mais que a Allevato. Já li alguns artigos de Ubiratã D'ambrósio, } \\
\text { Polya e TCCs aqui da Instituição que trata do assunto. }\end{array}$ & RP em TCC da instituição \\
\hline 9.14 & $\begin{array}{l}\text { Durante a disciplina de RP [...] alguns autores como Polya, Onuchic, } \\
\text { Allevato. TCCs que envolviam esta metodologia. }\end{array}$ & RP em TCC da instituição \\
\hline
\end{tabular}

Fonte: Elaborado pelos Autores

Por meio das respostas à questão 9, pretendemos levantar o conhecimento teórico dos estudantes sobre Resolução de Problemas acumulado ao longo do curso de Licenciatura em Matemática. Os referenciais teóricos, recuperados pela memória dos estudantes, algumas explicitadas no Quadro 4, constam no Quadro 5: livros, artigo e trabalhos de conclusão de curso (TCC), estes últimos produzidos no âmbito da Licenciatura em Matemática da instituição em que

5 Pseudônimo. 
os licenciandos estudam.

Quadro 5: Referências em Resolução de Problemas

ONUCHIC, Lourdes de la Rosa; ALLEVATO, Norma Suely Gomes; NOGUTI, Fabiane Cristina Höpner; JUSTULIN, Andresa Maria Justulin. (Org.). Resolução de Problemas: teoria e prática. Jundiaí: Paco Editorial, 2014

ONUCHIC, Lourdes de la Rosa; ALLEVATO, Norma Suely Gomes. Pesquisa em Resolução de Problemas: caminhos, avanços e novas perspectivas. Bolema, Rio Claro, v. 25, n. 41, p. 73-98, dez. 2011.

PÓLYA, George. How to solve it. Princeton: Princeton University Press, 1945.

MIRANDA, Ada Cristina de; VIEIRA, Inês Xavier; SILVA, Ronaldo Martins da. Ler, escrever e resolver problemas geométricos: uma investigação com alunos de ensino médio. 2018. Trabalho de Conclusão de Curso (Licenciatura em Matemática) - Instituto Federal de Educação, Ciência e Tecnologia de Minas Gerais. São João Evangelista.

FRANÇA, Keila Rodrigues; SILVA, Silvana Marçal da. Investigando estratégias usadas por alunos na resolução de situações-problemas que envolvem funções. 2018. Trabalho de Conclusão de Curso (Licenciatura em Matemática) - Instituto Federal de Educação, Ciência e Tecnologia de Minas Gerais. São João Evangelista

Fonte: Dados da Pesquisa

Quadro 6: Unidades de significado nas respostas à questão 10

QUESTÃO 10. Você se recorda se em alguma disciplina da Licenciatura em Matemática foi utilizada a metodologia de ensino-aprendizagem-avaliação de Matemática através da resolução de problemas para trabalhar algum conteúdo matemático? ( ) Sim. ( ) Não. Se sim, comente.

\begin{tabular}{|c|l|l|}
\hline $\begin{array}{l}\text { Código } \\
\text { da US }\end{array}$ & \multicolumn{1}{|c|}{ Fragmentos de textos das respostas dos estudantes } & \multicolumn{1}{|c|}{$\begin{array}{c}\text { Título da US } \\
\text { (Interpretações } \\
\text { preliminares dos } \\
\text { pesquisadores) }\end{array}$} \\
\hline 10.2 & $\begin{array}{l}\text { Sim. Estudamos sobre (grifo nosso) o assunto nas disciplinas: "Ensino de } \\
\text { Estatística e Matemática Financeira" e "RP" [...] vídeo introdutório com a } \\
\text { Dra. Onuchic. }\end{array}$ & $\begin{array}{l}\text { Ensino sobre RP em } \\
\text { disciplinas de Prática } \\
\text { como Componente } \\
\text { Curricular (PCC) e } \\
\text { Metodologias }\end{array}$ \\
\hline 10.7 & Sim. Em Geometria, Cálculo. & $\begin{array}{l}\text { Problemas em disciplinas } \\
\text { da Matemática }\end{array}$ \\
\hline 10.10 & $\begin{array}{l}\text { Sim. Muitas disciplinas utilizam a Metodologia da RP, como Matemática } \\
\text { Financeira, que faz um contraponto com assuntos sobre economia e } \\
\text { política. }\end{array}$ & $\begin{array}{l}\text { Ideia de problema } \\
\text { associada a contextos da } \\
\text { vida real, em disciplinas } \\
\text { do núcleo de Matemática }\end{array}$ \\
\hline 10.11 & $\begin{array}{l}\text { Sim. [...] durante as oficinas que nós estudantes aplicamos aos alunos da } \\
\text { Educação Básica. Nós não fomos avaliados dessa forma. (Grifo nosso). }\end{array}$ & $\begin{array}{l}\text { RP apenas nas oficinas } \\
\text { para alunos da Educação } \\
\text { Básica }\end{array}$ \\
\hline 10.12 & $\begin{array}{l}\text { Sim. Vimos na disciplina de Ensino de Estatística e Matemática } \\
\text { Financeira. }\end{array}$ & $\begin{array}{l}\text { RP em disciplinas do } \\
\text { núcleo de PCC }\end{array}$ \\
\hline 10.15 & $\begin{array}{l}\text { Sim. Além do nosso professor, atualmente, inserir resoluções de } \\
\text { RP apenas em disciplinas }\end{array}$ \\
\hline
\end{tabular}


problemas nos nossos projetos (apenas como aprendizagem) (grifo

do núcleo de PCC

nosso), [...] matérias como Ensino de Educação Estatística e Matemática

Financeira, o que contribuiu muito com os alunos da EJA.

Fonte: Elaborado pelos Autores

Quadro 7: Unidades de significado nas respostas à questão 11

QUESTÃO 11. Durante a Licenciatura em Matemática, você vivenciou ou testemunhou alguma experiência de aplicação de Resolução de Problemas em aulas de Matemática no Ensino Fundamental e/ou Médio?

( ) Sim. ( ) Não. Se sim, relate como foi.

\begin{tabular}{|c|c|c|}
\hline $\begin{array}{l}\text { Código } \\
\text { da US }\end{array}$ & Fragmentos de textos das respostas dos estudantes & $\begin{array}{l}\text { Título da US } \\
\text { (Interpretações } \\
\text { preliminares dos } \\
\text { pesquisadores) }\end{array}$ \\
\hline 11.2 & $\begin{array}{l}\text { Sim. Ao aplicar oficinas sobre Educação Financeira para } 01^{\circ} \text { ano [do } \\
\text { Ensino Médio] e sobre Música e Matemática para o } 9^{\circ} \text { ano[...] questões } \\
\text { contextualizadas; [...]deixar escrito todo seu raciocínio. }\end{array}$ & $\begin{array}{l}\text { RP em oficinas na } \\
\text { Educação Básica com } \\
\text { contextos da vida real e } \\
\text { escrita Matemática }\end{array}$ \\
\hline 11.3 & $\begin{array}{l}\text { Sim. Durante a regência no Estágio Supervisionado II [...]. E também na } \\
\text { disciplina Ensino de Educação Financeira e Educação Estatística. }\end{array}$ & $\begin{array}{l}\text { Práticas de Formação no } \\
\text { Estágio Supervisionado II } \\
\text { e em disciplinas do núcleo } \\
\text { PCC }\end{array}$ \\
\hline 11.4 & $\begin{array}{l}\text { Não. Em oportunidades que estive em sala, geralmente ocorria resolução } \\
\text { de lista. }\end{array}$ & $\begin{array}{lr}\text { Observação no } & \text { Estágio } \\
\text { Supervisionado: } & \text { não } \\
\text { ocorrência de RP. }\end{array}$ \\
\hline 11.8 & $\begin{array}{l}\text { Sim. No PIBID, atividades dadas pelos professores em aula de Geometria, } \\
\text { Análise Combinatória, Juros. }\end{array}$ & $\begin{array}{l}\text { Acompanhamento de } \\
\text { turmas no PIBID: RP com } \\
\text { contextos da vida real }\end{array}$ \\
\hline 11.10 & $\begin{array}{l}\text { Sim. Eu sou residente [...]; no período da realização da regência [...]tive } \\
\text { ajuda do nosso supervisor, adepto à RP[...] }\end{array}$ & $\begin{array}{l}\text { RP na regência de aulas } \\
\text { no programa Residência } \\
\text { Pedagógica }\end{array}$ \\
\hline 11.13 & $\begin{array}{l}\text { Sim. Quando atuava no PIBID, meu professor supervisor apresentou uma } \\
\text { situação problema e instigou os alunos a resolverem ela usando as } \\
\text { ferramentas que eles já tinham. }\end{array}$ & $\begin{array}{l}\text { Acompanhamento de } \\
\text { turmas no PIBID: RP } \\
\text { partindo de onde os } \\
\text { alunos estão. }\end{array}$ \\
\hline 11.14 & $\begin{array}{l}\text { Sim. Apenas durante a realização do Estágio Supervisionado II onde era } \\
\text { necessário montar planos de aula que abordassem essa metodologia [...] } \\
\text { Porém nunca presenciei algum professor trabalhar esta metodologia no } \\
\text { Ensino Fundamental ou Médio. }\end{array}$ & $\begin{array}{l}\text { RP no Estágio } \\
\text { Supervisionado e não } \\
\text { ocorrência na prática do } \\
\text { professor regente }\end{array}$ \\
\hline 11.17 & $\begin{array}{l}\text { Sim. Durante a aplicação de oficinas em algumas disciplinas, [...] foram } \\
\text { aplicadas situações problemas para fixar o que o aluno aprendeu. }\end{array}$ & $\begin{array}{l}\text { Oficinas na Educação } \\
\text { Básica com abordagem } \\
\text { clássica (tradicional) da } \\
\text { RP }\end{array}$ \\
\hline
\end{tabular}

Fonte: Elaborado pelos Autores 
Quadro 8: Unidades de significado nas respostas à questão 12

QUESTÃO 12. Você considera importante, para os alunos do Ensino Fundamental e Médio, que o professor trabalhe com a Resolução de Problemas nas aulas de Matemática? ( ) Sim. ( ) Não. Comente.

\begin{tabular}{|c|c|c|}
\hline $\begin{array}{l}\text { Código } \\
\text { da US }\end{array}$ & Fragmentos de textos das respostas dos estudantes & $\begin{array}{l}\text { Título da US } \\
\text { (Interpretações } \\
\text { preliminares dos } \\
\text { pesquisadores) }\end{array}$ \\
\hline 12.1 & $\begin{array}{l}\text { Sim. Pois é uma forma diferente de se passar o conteúdo, em que o aluno } \\
\text { consegue relacionar o conteúdo com a vida e seu cotidiano e aprender de } \\
\text { formas diferentes. }\end{array}$ & $\begin{array}{l}\text { Ensinar e aprender de } \\
\text { formas diferentes com } \\
\text { contextos da vida real }\end{array}$ \\
\hline 12.3 & $\begin{array}{l}\text { Sim. Eu acho de extrema importância, pois, antes de iniciar o conteúdo, os } \\
\text { alunos têm a oportunidade de compreender e dar sentido ao que será } \\
\text { ensinado. Deixam seus pseudoconhecimentos e formalizam a linguagem } \\
\text { Matemática por meio da mediação do professor e dos diálogos } \\
\text { estabelecidos durante a resolução. Além disso, durante a plenária os } \\
\text { alunos possuem mais autonomia. }\end{array}$ & $\begin{array}{l}\text { Novos papéis do } \\
\text { professor e do aluno no } \\
\text { ensino através da RP }\end{array}$ \\
\hline 12.8 & Sim. [...] força o aluno a pensar sobre a solução para o problema. & Sobre o que é problema \\
\hline 12.9 & $\begin{array}{l}\text { Sim. Ao utilizar esse método no estágio, notei que os estudantes criam } \\
\text { mais interesse nas aulas ao serem forçados a pensar e explorar suas } \\
\text { habilidades Matemáticas. }\end{array}$ & $\begin{array}{l}\text { Mobilização de interesse, } \\
\text { criatividade e habilidade } \\
\text { Matemática, } \\
\text { atividades do } \\
\text { Suptágio } \\
\text { Suprvisionado }\end{array}$ \\
\hline 12.12 & $\begin{array}{l}\text { Sim. Pois os alunos podem mostrar vários meios de resolver um problema } \\
\text { e não ficam espelhados só no modelo do professor. }\end{array}$ & $\begin{array}{l}\text { Criatividade e autonomia } \\
\text { do aluno na RP }\end{array}$ \\
\hline 12.1 & $\begin{array}{l}\text { Sim. Os alunos não ficam presos em fórmulas e decoreba; [...] } \\
\text { desenvolvem ferramentas que ajudam a chegar na solução do problema. }\end{array}$ & Criatividade na RP \\
\hline 12.16 & [...] situações que se adequam ao contexto sociocultural de cada um. & $\begin{array}{l}\text { Problemas e contextos da } \\
\text { vida real }\end{array}$ \\
\hline
\end{tabular}

Fonte: Elaborado pelos Autores

Quadro 9: Unidades de significado nas respostas à questão 13

QUESTÃO 13. Você acredita ser capaz de elaborar um plano de aula fundamentado na metodologia de ensinoaprendizagem-avaliação de Matemática através da resolução de problemas, para regência em turmas de Ensino Fundamental e/ou Médio? ( ) Sim. ( ) Não. Comente.

Código da US Fragmentos de textos das respostas dos estudantes

\section{Título da US (Interpretações preliminares dos pesquisadores)}

13.1 Sim. Pelo que foi visto na disciplina RP, me considero com a capacidade de elaborar um plano; [...] ainda é preciso fazer mais pesquisas e ler mais sobre 0 assunto.
Formação inicial em RP para a prática docente na disciplina RP 


\begin{tabular}{|c|l|l|}
\hline 13.2 & $\begin{array}{l}\text { Sim. [...] já construí um plano para meu Estágio Supervisionado II. O } \\
\text { problema é fazer o aluno se desligar das fórmulas e de querer as questões } \\
\text { "mastigadas". }\end{array}$ & $\begin{array}{l}\text { Experiência no Estágio } \\
\text { Supervisionado sobre a } \\
\text { conjecturas prática } \\
\text { inovação na } \\
\text { docente }\end{array}$ \\
\hline 13.7 & $\begin{array}{l}\text { Sim. Foi solicitada a elaboração de um plano de aula fundamentado nessa } \\
\text { metodologia no Estágio II. }\end{array}$ & $\begin{array}{l}\text { Estágio Supervisionado: } \\
\text { oportunidade de vivência } \\
\text { de metodologias de } \\
\text { ensino }\end{array}$ \\
\hline 13.8 & $\begin{array}{l}\text { Sim. Após a disciplina de RP, acredito que seja possível. } \\
\text { Formação inicial em RP } \\
\text { para prática docente, na } \\
\text { disciplina RP }\end{array}$ \\
\hline
\end{tabular}

Fonte: Elaborado pelos Autores

Com o Quadro 9, concluímos a apresentação das Unidades de Significado que serão reunidas em categorias na próxima seção.

\subsection{Categorização}

Tendo procedido à fragmentação de todo o corpus da pesquisa - as respostas dos 17 participantes às questões de 1 a 15 , do questionário aplicado — chegamos inicialmente a um total aproximado de 120 unidades de significado (US), que foram devidamente codificadas e nomeadas. A partir desses dados, procuramos identificar categorias evidenciadas nas falas dos participantes da pesquisa. Percebemos duas categorias emergiam dos dados: 1. Concepções de/sobre Resolução de Problemas; 2. Resolução de Problemas na Formação Inicial e Iniciação à Docência. Para fins deste artigo, buscamos selecionar um subconjunto do universo de unidades de significado que ilustrasse de forma mais abrangente essas categorias consideradas. Assim, compusemos o conjunto final de 36 unidades de significado, referentes especificamente às perguntas de 8 a 13, apresentadas nos Quadros 3 a 9 . O que se deu, portanto, foi que, a partir da impregnação no corpus da pesquisa, fomos levados à opção pelo método indutivo — do particular ao geral - à definição das categorias. A partir de conhecimentos tácitos dos pesquisadores, consideramos as categorias emergentes da fragmentação dos textos, que devem sempre estar em consonância com os objetivos da pesquisa (MORAES e GALLIAZI, 2016).

A categorização é, pois, a etapa onde se estabelecem relações entre as unidades de significado, "combinando-as e classificando-as, reunindo esses elementos unitários na formação de conjuntos que congregam elementos próximos, resultando daí sistemas de categorias" 
(MORAES e GALLIAZI, 2016, p. 34). Assim, sugestionados por Vieira (2016) e Andreatta e Allevato (2020), organizamos os sistemas de categorias no Quadro 10, em cujo cabeçalho explicitamos a questão norteadora da pesquisa, apresentada aos participantes por ocasião da aplicação do questionário.

Quadro 10: Unidades de significado (US) agrupadas em categorias

\begin{tabular}{|c|c|c|}
\hline Unidades de Significado & Subcategorias & Categorias de Análise \\
\hline $\begin{array}{c}8.2 ; 8.3 ; 8.5 ; 10.10 ; 11.2 ; 12.1 ; \\
12.16\end{array}$ & $\begin{array}{l}\text { Ideia de problema relacionada a } \\
\text { enunciados com contextos da vida } \\
\text { real }\end{array}$ & \multirow{4}{*}{$\begin{array}{c}\text { Concepções de/sobre Resolução } \\
\text { de Problemas }\end{array}$} \\
\hline $10.11 ; 10.12 ; 10.15 i ; 10.15 ; 13.8$ & Ensino sobre RP & \\
\hline $8.2 ; 8.5 ; 8.17 ; 10.7 ; 11.4 ; 11.17$ & $\begin{array}{c}\text { Ensino para rp: ensino tradicional } \\
\text { de Matemática }\end{array}$ & \\
\hline $\begin{array}{c}\text { 8.3; 8.13; 10.11; } 11.13 ; 12.1 ; 12.3 ; \\
12.12 ; 12.13\end{array}$ & Ensino através da rp & \\
\hline $\begin{array}{c}11.2 ; 11.3 ; 11.4 ; 11.14 ; 12.9 ; 13.2 \\
13.6\end{array}$ & Estágio Supervisionado & \multirow{5}{*}{$\begin{array}{l}\text { Resolução de Problemas na } \\
\text { Formação Inicial e Iniciação à } \\
\text { docência }\end{array}$} \\
\hline $\begin{array}{l}\text { 8.11; 8.13; 8.15; } 9.14 ; 10.2 ; 10.11 \\
\quad \text { 10.12; } 11.2 ; 11.3 ; 13.1 ; 13.8\end{array}$ & $\begin{array}{c}\text { Práticas de formação nas } \\
\text { disciplinas de PCC e Metodologias }\end{array}$ & \\
\hline $11.8 ; 11.10 ; 11.13$ & $\begin{array}{c}\text { Programas institucionais: } \\
\text { Residência Pedagógica e PIBID }\end{array}$ & \\
\hline $9.4 ; 9.10 ; 9.14$ & Pesquisa acadêmica: RP em TCCs & \\
\hline $12.1 ; 12.3 ; 12.8 ; 12.9 ; 12.12 ; 12.13$ & $\begin{array}{l}\text { Inovação nos processos de ensino } \\
\text { e aprendizagem }\end{array}$ & \\
\hline
\end{tabular}

Fonte: Elaborado pelos Autores

Após a organização das unidades de significado em subcategorias e categorias, no Quadro 10, partimos para a comunicação da pesquisa, na próxima seção.

\subsection{Comunicação dos dados}

A comunicação da pesquisa acontece por meio da elaboração dos metatextos, que contêm as interpretações dos pesquisadores, análise dos dados e elaboração de argumentos, ou seja, a teorização, sempre tendo em vista o projeto de pesquisa em que as análises se inserem. 


\begin{abstract}
A Análise Textual Discursiva tem no exercício da escrita seu fundamento enquanto ferramenta mediadora na produção de significados e por isso, em processos recursivos, a análise se desloca do empírico para a abstração teórica, que só pode ser alcançada se o pesquisador fizer um movimento intenso de interpretação e produção de argumentos. (MORAES e GALIAZZI, 2006, p. 18)
\end{abstract}

Tendo elegido as categorias 1. Concepções de/sobre Resolução de Problemas e 2. Resolução de Problemas na Formação Inicial e Iniciação à Docência, apresentamos, a seguir, os argumentos a partir da aproximação das unidades de significado semelhantes.

A fim de discutirmos as observações feitas no contexto da primeira categoria, necessário se faz esclarecer alguns pontos sobre a matriz curricular da Licenciatura em Matemática da instituição em que foi realizada essa pesquisa. O perfil de formação dos estudantes é constituído por disciplinas organizadas em 7 núcleos, quais sejam: (1) Matemática; (2) Pedagógicas; (3) Prática como Componente Curricular; (4) Metodologias; (5) Pesquisa - TCC; (6) Optativas; e, (7) Outros (IFMG, 2018, p. 32).

Nos dados que apresentamos as experiências com Resolução de Problemas foram relatadas em duas frentes. Em relação às disciplinas do núcleo de Matemática (Álgebra Linear; Matemática Financeira; Teoria dos Números; Estatística; Cálculo), o que levantamos nos relatos dos participantes é a predominância do ensino para a resolução de problemas, sendo relacionada, neste caso, à ideia de enunciados com contextos da vida real que é, ainda, frequentemente associada à compreensão do que é problema; além do que, trata-se de uma prática clássica, ou tradicional, na abordagem de conteúdos matemáticos. 0 que se percebe é que os licenciandos relacionam 0 ato de resolver problemas contextualizados à Resolução de Problemas como metodologia de ensino de Matemática, uma compreensão teórica limitada que confirma a necessidade de aprofundamento no tema: um problema pode sim ser puramente matemático, embora a contextualização seja interessante e, não raro, relevante no ensino. A outra referência à Resolução de Problemas na graduação deu-se com relação às disciplinas do núcleo das Práticas como Componente Curricular (Ensino de Estatística e Matemática Financeira) e do núcleo Metodologias (Resolução de Problemas) que se constituíram em oportunidades de experiências de ensino sobre a Resolução de Problemas e de ensino através da resolução de problemas.

Destaque-se que os estudantes mencionaram, sem diferenciação explícita, as três formas de realizar um trabalho em sala de aula de Matemática, citadas por Allevato e Onuchic (2014): i) ensino sobre Resolução de Problemas; ii) ensino para a resolução de problemas; e, iii) ensino através da resolução de problemas. Em disciplinas dos núcleos PCC e Metodologias (Ensino de 
Estatística e Matemática Financeira; Resolução de Problemas) fazem referência ao ensino sobre Resolução de Problemas e através da resolução de problemas. E, ainda, mencionam o ensino para a resolução de problemas associados a contextos reais, em disciplinas do núcleo Matemática (Geometria; Cálculo; Matemática Financeira), o que evidencia que os estudantes não fazem clara diferenciação entre as três abordagens citadas acima. Também não houve evidências de que a definição de problema, conforme Van de Walle (2009) ou Allevato e Onuchic (2014), tenha sido considerada.

"Nós não fomos avaliados dessa forma" (US 10.11) e "[...] apenas como aprendizagem" (US 10.15) são falas que fazem referência ao ensino sobre Resolução de Problemas. O que se percebe nessas US é uma convergência em afirmar que, enquanto alunos da licenciatura, práticas de ensino-aprendizagem-avaliação através da resolução de problemas em conteúdos do núcleo Matemática não foram vivenciadas, o que se configura como um risco de que se constitua a compreensão da impossibilidade de praticá-lo em contextos rotineiros de sala de aula da Educação Básica. O ensino através da resolução de problemas foi relacionado pelos estudantes às disciplinas da Prática como Componente Curricular. Observamos que os licenciandos percebem as disciplinas do núcleo da Matemática como espaços para praticar a concepção tradicional de ensino de Matemática (ensino para a resolução de problemas) enquanto o ensino através da resolução de problemas esteve, todo o tempo, vinculado às disciplinas Resolução de Problemas e àquelas do núcleo de PCC.

Em relação à segunda categoria, que reuniu unidades de significado referentes a experiências com a Resolução de Problemas em práticas de iniciação à docência, iniciamos com atividades de observação, no Estágio Supervisionado, destacando a fala do estudante que relata não ter testemunhado o trabalho com Resolução de Problemas na Educação Básica. Isso sugere que no ensino de Matemática atual e usualmente realizado ainda não se percebe que a Resolução de Problemas, como metodologia de ensino, tenha sido implementada como prática comum aos professores em exercício (US 11.4). No entanto, enquanto estagiários ou alunos de disciplinas do núcleo PCC, durante a regência de aulas ou realização de oficinas na Educação Básica, os licenciandos implementaram planos de aula elaborados na perspectiva do ensino-aprendizagemavaliação através da resolução de problemas. Aqui se observa a relevância das atividades de iniciação à docência, como oportunidade de desenvolver práticas de formação em metodologias de ensino. 
Nas experiências na regência de aula, no contexto do programa Residência Pedagógica, por outro lado, um único estudante entre os 17 participantes, que à época da aplicação do questionário havia participado da edição 2018-2020 do programa institucional, destacou que a adesão do professor da Educação Básica à Resolução de Problemas o incentivou a implementar planos de aula com base na metodologia (US 11.10). Nesse conjunto de estudantes, outros relataram o contato com a Resolução de Problemas nas atividades de iniciação à docência: (a) PIBID; (b) Estágio Supervisionado, com a elaboração e realização de planos de aula baseados em Resolução de Problemas; e, (c) disciplinas de PCC, nas atividades de prática de formação, com oficinas aplicadas a turmas da Educação Básica. No entanto, a US 11.17 evidencia a replicação do ensino tradicional de Matemática, em oportunidade de regência de aula, no âmbito do Estágio Supervisionado: o ensino para a resolução de situações-problema, para "fixar o que 0 aluno aprendeu" (US 11.17).

Na US 12.3, observamos uma compreensão mais próxima do que vem a ser o ensinoaprendizagem-avalição de Matemática através da resolução de problemas. Elementos e etapas do processo, segundo Allevato e Onuchic (2014), são elucidadas na fala do estudante: apresentação do problema anteriormente à exposição do conteúdo (etapa 1); antecipação de atribuição de significado, pelo aluno, ao conteúdo que será formalizado a posteriori; formalização da linguagem Matemática, com a mediação do professor (novo papel para o professor); aprendizagem dialógica, colaborativa e cooperativa; na plenária (etapa 7), desenvolvimento da autonomia (novo papel para o aluno).

Sobre a importância da Resolução de Problemas na Educação Básica, houve unanimidade. Os participantes da pesquisa consideram importante a inovação metodológica com o ensino através da resolução de problemas. Os papéis de alunos e professor no processo evidenciam vantagens didáticas com o trabalho com Resolução de Problemas. Os participantes consideram a importância do ensino-aprendizagem-avaliação de Matemática através da resolução de problemas na Educação Básica como recurso para promover formas diferentes de ensinar e aprender. Aqui, fica evidente que a inovação metodológica, segundo relataram os estudantes, acontece quando a perspectiva da Resolução de Problemas é adotada. Aspectos da metodologia são destacados: o desenvolvimento da criatividade e aumento do interesse dos alunos, e o dar sentido ao que será ensinado/aprendido (US 12.3).

Sobre a segurança para a elaboração de planos de aula na perspectiva da Resolução de 
Problemas, dos 17 estudantes participantes, apenas dois afirmaram não se sentirem preparados para essa tarefa/prática. Todos os outros afirmaram ser capazes de fazê-lo, devido ao trabalho realizado na disciplina Resolução de Problemas, do núcleo Metodologias, nas disciplinas do núcleo de PCC e a partir das experiências com elaboração e execução de planos de aula durante o Estágio Supervisionado.

É fato que o processo de planejamento de uma aula de Matemática exige do professor um conjunto de conhecimentos importantes (GODINO, 2009). Nesse contexto, destaca-se o conhecimento matemático que possibilita ao professor realizar as escolhas dos problemas, bem como abordá-lo com o rigor científico requerido. Ainda, espera-se que, ao planejar uma aula, o professor seja capaz de selecionar os instrumentos necessários, especialmente, por exemplo, aqueles que remetem ao uso da tecnologia. A questão da reflexão sobre a avaliação também é fundamental ao ato de planejar, pois, assim, o professor pode reconhecer as potencialidades e os limites dos processos de ensino e de aprendizagem e redirecioná-los, se necessário.

Ao planejar a aula é importante levar em consideração, ainda, que o desenrolar da aula de Matemática é constituído por um amálgama de elementos do campo da afetividade, entre eles, as crenças, os valores, as atitudes e as emoções que, na visão de Pino-Fan e Godino (2015) podem ser decisivos para o estudante aprender, ou não. Outros fatores são igualmente estratégicos, como as relações que podem ser estabelecidas entre os atores ao longo de uma aula, bem como o contexto da instituição educacional.

Encerramos esta seção ressaltando, ainda, que, ainda que, conforme manifestaram os licenciandos, a disciplina Resolução de Problemas tenha introduzido o tema ensino através de resolução de problemas, admite-se a necessidade de aprofundamento no tema para a elaboração de planos de aula (US 13.1). O Estágio Supervisionado configurou-se como oportunidade de elaboração e implementação de planos de aula com Resolução de Problemas e a iniciação à docência, nessas ocasiões, permitiu ao futuro professor conjecturar sobre práticas docentes inovadoras e sobre o comportamento do aluno diante delas. "O problema é fazer 0 aluno se desligar das fórmulas" (US 13.2).

\section{Considerações Finais}

A urgência e a necessidade da abordagem, junto à Formação Inicial de Professores, de metodologias de ensino de Matemática que promovem a construção e a participação ativa dos 
estudantes evidenciam a importância desta pesquisa. Professores bem formados, desde a graduação, tenderão a fazer a diferença na revolução da sala de aula, em prol da garantia dos direitos de aprendizagem de todos os alunos matriculados na Educação Básica.

Reconhecemos a importância das reflexões curriculares, tanto no âmbito da Educação Básica, quanto na formação de professores, porém, estas necessitam reconhecer as práticas culturais e as regionalidades. Além disso, o diálogo com as comunidades escolares e acadêmicas é fundamental para o processo de legitimação das mudanças nos currículos, em especial, o de Matemática.

Os futuros professores perceberam as habilidades que podem ser desenvolvidas pela Resolução de Problemas, enquanto ação e metodologia: criatividade, ao abrir mão de modelos prontos apontados pelo professor; autonomia, ao buscar caminhos e ferramentas próprias para encontrar a solução; interpretação/compreensão de textos e contextos (materacia); disposição para o debate, para a troca de opinião, para a interação/socialização e para o trabalho em grupo.

A aula de Matemática desenvolvida segundo as etapas da Resolução de Problemas, como recomendam Allevato e Onuchic (2014), torna o ambiente favorável ao aumento do interesse do aluno pela Matemática, bem como propicia uma revisão do papel da memória e das fórmulas na compreensão dos conceitos e na aprendizagem dos conteúdos. Segundo previsto na décima etapa, a proposição/elaboração de novos problemas, especialmente pelos alunos, além de sugerir o reinício do ciclo, vem se constituindo como um tema de investigação na Educação Matemática e, portanto, trata-se de um assunto importante para pesquisas futuras.

Em todo o processo de ensino-aprendizagem-avaliação de Matemática através da resolução de problemas o papel do professor é revisto, a necessidade dos conhecimentos especializados fica evidente e a Matemática passa a fazer sentido para o aluno, quando aquele inverte a ordem institucionalizada nas aulas de Matemática, que parte da apresentação formal do conteúdo matemático e segue para resolução de problemas de aplicação, em detrimento de uma nova ordem: alunos autônomos, tendo um problema em mãos como ponto de partida para fazer Matemática, e um professor gerenciando o processo recursivo de ensinar, aprender, avaliar, reensinar, reaprender... 


\section{Agradecimentos}

A primeira autora agradece à Coordenação de Aperfeiçoamento de Pessoal de Nivel Superior (CAPES) pelo apoio financeiro dado ao convênio firmado entre a Universidade Cruzeiro do Sul (UNICSUL) e o IFMG, e ao campus São João Evangelista do IFMG pelo afastamento concedido para qualificação.

\section{Referências}

ALLEVATO, Norma Suely Gomes; ONUCHIC, Lourdes de la Rosa. As conexões trabalhadas através da resolução de problemas na formação inicial de professores de Matemática. REnCiMa, São Paulo, v. 10, n. 2. p. 1-14, 2019.

ALLEVATO, Norma Suely Gomes; ONUCHIC, Lourdes de la Rosa. Ensino-aprendizagemavaliação de Matemática: por que através da resolução de problemas. In: ONUCHIC, Lourdes de la Rosa; ALLEVATO, Norma Suely Gomes; NOGUTI, Fabiane Cristina Höpner; JUSTULIN, Andresa Maria Justulin. (Org.). Resolução de Problemas: teoria e prática. Jundiaí: Paco Editorial, 2014, p. 35-52.

ANDREATTA, Cidimar; ALLEVATO, Norma Suely Gomes. Aprendizagem matemática através da elaboração de problemas em uma escola comunitária rural. Educação Matemática Debate, Montes Claros, v. 4, p. 1-23, abr. 2020.

BALL, Deborah Loewenberg; THAMES, Mark Hoover; PHELPS, Geoffey. Content knowledge for teaching: what makes it special? Journal of Teacher Education, Ann Arbor, v. 59, n. 5, p. 389-407, nov. 2008.

BICALHO, Jossara Bazílio de Souza. A Resolução de Problemas na Formação inicial de professores de Matemática: percepções dos bolsistas do programa Residência Pedagógica. In: ENCONTRO BRASILEIRO DE ESTUDANTES DE PÓS-GRADUAÇÃO EM EDUCAÇÃO MATEMÁTICA, 22, 2018, Belo Horizonte. Anais do $22^{\circ}$ EBRAPEM: Pesquisa em Educação Matemática e Inclusão Social. Belo Horizonte: UFMG, 2018, p. 1-12.

BRASIL. Resolução CNE/CP $n^{0}$ 2, de 20 de dezembro de 2019. Define as Diretrizes Curriculares Nacionais para a Formação Inicial de Professores para a Educação Básica e institui a Base Nacional Comum para a Formação Inicial de Professores da Educação Básica (BNC-Formação). Brasília: Diário Oficial da União, 10 fev. 2020.

BREDA, Adriana; FONT, Vicenç; LIMA, Valderez Marina do Rosário; PEREIRA, Marcos Vilella. Componentes e indicadores de los criterios de idoneidad didáctica desde la perspectiva del enfoque ontosemiótico. Transformación, Camagüey, vol. 14, n. 2, p. 162-176, ago. 2018.

CAI, Jinfa; LESTER, Frank. Por que o ensino com Resolução de Problemas é importante para a aprendizagem do aluno? Tradução de Antônio Sérgio Abraão Monteiro Bastos e Norma Suely Gomes Allevato. Boletim GEPEM, Rio de Janeiro, n. 60, p. 241-254, 2012. 
CARRILLO, José; CLIMENT, Nuria; CONTRERAS, Luis; MONTES, Miguel. Mathematics teachers' specialised knowledge in managing problem-solving classroom tasks. In: FELMER, Patrício; LILJEDAHL, Peter; KOICHU, Boris (Ed.). Problem Solving in Mathematics Instruction and Teacher Professional Development. Switzerland: Springer, 2019, p. 297-316.

ERNEST, Paul. Reflections on theories of learning. In: SRIRAMAN, Bharath; ENGLISH, Lyn. (Ed.). Theories of Mathematics Education: seeking new frontiers. Switzerland: Springer, 2010, p. 39-47.

FELMER, Patricio; PERDOMO-DÍAZ, Josefa. Novice Chilean Secondary Mathematics Teachers as Problem Solvers. In: FELMER, Patricio; PEHKONEN, Erkki; KILPATRICK, Jeremy. (Ed.). Posing and solving problems: advances and new perspectives. Switzerland: Springer, 2016. p. 287-308.

GODINO, Juan Díaz. Categorías de análisis de los conocimientos del profesor de Matemáticas. Unión, San Cristóbal de La Laguna, v. 5, n. 20, p. 13-31, dic. 2009.

GODINO, Juan Díaz; GIACOMONE, Belén; BATANERO, Carmen; FONT, Vincenç. Enfoque Ontosemiótico de los Conocimientos y Competencias del Profesor de Matemáticas. Bolema, Rio Claro, v. 31, n. 57, p. 90-113, abr. 2017.

GROSSMAN, Pamela. The making of a teacher: teacher knowledge and teacher education. New York: Teachers College Press, 1990.

IFMG - INSTITUTO FEDERAL DE EDUCAÇÃO, CIÊNCIA E TECNOLOGIA DE MINAS GERAIS, CAMPUS SÃO JOÃO EVANGELISTA. Projeto Pedagógico do Curso de Licenciatura em Matemática. São João Evangelista: IFMG/SJE, 2018.

KAIBER, Carmen Teresa; LEMOS, Andrielly Viana; PINO-FAN, Luis. Enfoque Ontossemiótico do Conhecimento e da Instrução Matemática (EOS): um panorama das pesquisas na América Latina. Perspectivas da Educação Matemática, Campo Grande, v. 10, n. 23, p. 531-552, maio/ago. 2017.

MORAES, Roque; GALIAZZI, Maria do Carmo. Análise Textual Discursiva. 3. ed. ljuí: Unijuí, 2016.

MORIEL JUNIOR, Jeferson Gomes; WIELEWSKI, Gladys Denise. Base de conhecimento de professores de Matemática: do genérico ao especializado. Revista de Ensino, Educação e Ciências Humanas, Londrina, v. 18, n. 2, p. 126-133, 2017.

ONUCHIC, Lourdes de la Rosa; ALLEVATO, Norma Suely Gomes. Novas reflexões sobre o ensino-aprendizagem de Matemática através da Resolução de Problemas. In: BICUDO, Maria Aparecida Viggiani; BORBA, Marcelo de Carvalho. (Org.). Educação Matemática: pesquisa em movimento. 4. ed. São Paulo: Cortez, 2012, p. 232-252.

ONUCHIC, Lourdes de la Rosa; ALLEVATO, Norma Suely Gomes. Pesquisa em Resolução de Problemas: caminhos, avanços e novas perspectivas. Bolema, Rio Claro, v. 25, n. 41, p. 73-98, dez. 2011.

ONUCHIC, Lourdes de la Rosa; ALLEVATO, Norma Suely Gomes. Proporcionalidade através da Resolução de Problemas no curso superior de Licenciatura em Matemática. In: SEMINÁRIO 
INTERNACIONAL DE PESQUISA EM EDUCAÇÃO MATEMÁTICA, 6, 2015, Pirenópolis. Anais do $6^{\circ}$ SIPEM. Brasilia: SBEM, 2015, p. 1-12.

ONUCHIC, Lourdes de la Rosa; ALLEVATO, Norma Suely Gomes. Resolução de Problemas na Licenciatura em Matemática: rumo à compreensão e à aquisição das grandes ideias contidas na Matemática escolar. In: SEMINÁRIO INTERNACIONAL DE PESQUISA EM EDUCAÇÃO MATEMÁTICA, 4, 2009, Brasília. Anais do 4 SIPEM. Brasília: SBEM, 2009, p. 1-21.

PINO-FAN, Luis; FONT, Vincenç; GODINO, Juan Díaz. El conocimiento didáctico-matemático de los profesores: pautas y criterios para su evaluación y desarrollo. In: FLORES; Crisólogo Dolores; GONZÁLES; Maria del Socorro García; SANCHES; Judith Alejandra Hernández; GUERRERO, Leticia Sosa. (Ed.). Matemática Educativa: la formación de professores. México: Ediciones Díaz de Santos \& Universidad Autónoma de Guerrero, 2013, p. 137-151.

PINO-FAN, Luis; GODINO, Juan Díaz. Perspectiva ampliada del conocimiento didácticomatemático del profesor. Paradigma, Maracay, v. 36, n. 1, p. 87-109, jun. 2015.

PINO-FAN, Luis; GODINO, Juan Díaz; FONT, Vincenç. Faceta epistémica del conocimiento didáctico-matemático sobre la derivada. Educação Matemática Pesquisa, São Paulo, v. 13, n. 1, p. 141-178, jan./abr. 2011.

PÓLYA, George. How to solve it. Princeton: Princeton University Press, 1945.

RODRIGUES, Larissa Zancan; PEREIRA, Beatriz; MOHR, Adriana. O documento "Proposta para Base Nacional Comum da Formação de Professores da Educação Básica" (BNCFP): dez razões para temer e contestar a BNCFP. Revista Brasileira de Pesquisa em Educação em Ciências, Belo Horizonte, n. 20, p. 1-39, jan./dez. 2020.

SHULMAN, Lee. Knowledge and teaching: foundations of the new reform. Harvard Educational Review, Cambridge, v. 57, n. 1, p. 1-23, feb. 1987.

SHULMAN, Lee. Those who understand: knowledge growth in teaching. Educational Researcher, Washington, v. 15, n. 2, p. 4-14, feb. 1986.

SKOVSMOSE, Ole. Educação Matemática Crítica: a questão da democracia. 6. ed. Tradução de Abigail Lins e Jussara de Loiola Araújo. Campinas: Papirus, 2013.

VAN DE WALLE, John. Matemática no Ensino Fundamental: formação de professores e aplicação em sala de aula. 6. ed. Tradução de Paulo Henrique Colonesse. Porto Alegre: Artmed, 2009.

VIEIRA, Gilberto. Tarefas exploratório-investigativas e a construção de conhecimento sobre figuras geométricas espaciais. 2016. 169f. Tese (Doutorado em Ensino de Ciências e Matemática) - Universidade Cruzeiro do Sul. São Paulo. 